\title{
Separation Enhancement of Mechanical Filters by Adding Negative Air lons
}

\author{
Shinhao Yang ${ }^{1}$, Yi-Chin Huang ${ }^{1}$, Chin-Hsiang Luo, ${ }^{2, *}$ and Chi-Yu Chuang ${ }^{3}$ \\ ${ }^{1}$ Center for General Education, Toko University, Chiayi 61363, Taiwan \\ ${ }^{2}$ Department of Safety, Health and Environmental Engineering, Hungkuang University, Taichung 43302, \\ Taiwan \\ ${ }^{3}$ Department of Occupational Safety and Health, Chang Jung Christian University, Tainan 71101, Taiwan
}

\begin{abstract}
The purpose of this work is to combine negative air ions (NAls) and mechanical filters for removal of indoor suspended particulates. Various factors, including aerosol size $(0.05-0.45 \mu \mathrm{m})$, face velocity $(10$ and $20 \mathrm{~cm} / \mathrm{s})$, species of aerosol (potassium chloride and dioctyl phthalate), relative humidity ( $30 \%$ and $70 \%)$, and concentrations of NAls $(2 \times$ $10^{4}, 1 \times 10^{5}$, and $2 \times 10^{5} \mathrm{NAls} / \mathrm{cm}^{3}$ ) were considered to evaluate their effects on the aerosol collection characteristics of filters. Results show that the aerosol penetration through the mechanical filter is higher than that through the mechanical filters cooperated with NAls. This finding implies that the aerosol removal efficiency of mechanical filters can be improved by NAls. Furthermore, the aerosol penetration through the mechanical filters increased with the aerosol size when NAls were added. That is due to that the aerosol is easier to be charged when its size gets larger. The results also indicate the aerosol penetration decreased with the NAls concentration increased. Reversely, aerosol penetration through the mechanical filters increased with the face velocity under the influence of NAls. The aerosol penetration through the filter with NAls was no affected with relative humidity. Finally, The penetration through the filter with NAls against solid aerosol was lower than that against liquid aerosol.
\end{abstract}

Keywords: Negative air ions, Filtration, Aerosol penetration, Mechanical filter.

\section{INTRODUCTION}

On average, people spend as much as $87.2 \%$ of their time in indoor environment [1]. Hence indoor air quality has become an increasingly important problem. Indoor suspended particulates play a major role in indoor air quality because they cause many respiratory diseases [2-4]. Therefore, more and more air-cleaning technologies have been used to remove the indoor particulates.

Air filtration is an effective technique for removing aerosols from a gas stream. The key collection mechanism between particles and filters is the mechanical force. Traditionally, mechanical filters are often used in a heating, ventilating and air-conditioning (HVAC) system to remove indoor particulates. The mechanisms of mechanical filters for particle removal are only interception, inertial impaction, diffusion and gravitational settling.

Recently, the electrostatic capture forces, including dielectrophoretic, coulombic, and image capture forces [5], were applied in the filtration processes for increasing the aerosol collection efficiency. Several researches had investigated the electrostatic collection characteristics and filtration mechanism of electret

*Address correspondence to this author at the Department of Safety, Health and Environmental Engineering, Hungkuang University, Taichung 43302, Taiwan; Tel: 886-4-26318652; E-mail: andyluo@hk.edu.tw filters [6-12]. Luckner et al. [13] and Lee et al. [14] used an external electric field on the filter to increase the electrostatic force for removal of aerosols. Mermelstein et al. [15] observed that an external electric field added on the stainless steel filter provides the electrostatic capture capability for removal of aerosols. Yang and Lee [16] applied the surfactants coated on the surface of filter fibers to enhance the surface charges for raising the aerosol removal efficiency. Agranovski et al. [17] demonstrated that emission of air ions in the vicinity of a low-efficiency HVAC filter significantly improved the electrostatic capture force. All of these studies confirmed that coulombic and dielectrophoretic capture forces increased filtration efficiency of filters. However, the effect of the image capture force on the filtration is seldom studied.

Negative air ionizers have been applied to clean indoor air. Daniels [18] reported that negative air ions (NAls) reduced aerosol particles, airborne microbes, odors and volatile organic compounds (VOCs). NAls were of use to remove airborne particles [19-20]. Charging particles by emitted ions and electromigration was established as the removal mechanism supported by NAIs [21-22]. Interaction between charged particles and the electric field produced by electrical discharge increased the migration velocity towards the indoor surfaces, finally aerosols were deposited on various surfaces, such as wall surfaces [21-23]. However, the collected particles would stain the wall face. 
The purpose of this work is to combine NAls and mechanical filters to eliminate indoor suspended particulates. NAls caused the particles charged and provided the image capture force for mechanical filters to enhance their filtration capability. Charged aerosols are collected on the filters, and dirty surfaces cannot occur. Furthermore, the effects of face velocity, relative humidity, and the concentration of NAls on the aerosol collection characteristics were also considered.

\section{EXPERIMENTAL}

\subsection{Single-Fiber Efficiency Theory}

The theoretical aerosol penetration through a filter, in terms of total single-fiber efficiency is [5]:

$$
P=\exp \left(\frac{-4 \alpha E_{\sum} m}{\pi d_{f}(1-\alpha)}\right),
$$

where $P$ is the aerosol penetration through the filter; $E_{\Sigma}$ represents the total single-fiber efficiency; $d_{f}$ is the mean fiber diameter; $m$ is the filter thickness, and $\alpha$ is the fiber packing fraction. The total single-fiber efficiency of an electret filter is the sum of mechanical and electrostatic single-fiber efficiencies, expressed as

$$
E_{\Sigma}=1-\left(1-E_{M}\right)\left(1-E_{O}\right)\left(1-E_{C}\right)\left(1-E_{I M}\right),
$$

where $E_{\mathrm{M}}, E_{\mathrm{O}}, E_{\mathrm{C}}$ and $E_{I M}$ are the single-fiber efficiency due to the total mechanical, dielectrophoretic, coulombic, and image capture mechanisms, respectively. The overall mechanical mechanism involves diffusion, interception, impaction, and gravitational settling. The mechanical mechanisms of an electret filter are insignificant, and thus the total mechanical mechanism represents the effect of all mechanical mechanisms. Equation (2) assumes independence of all mechanisms.

\subsection{Test Filters}

Polypropylene fibrous filters were employed in this study. The characteristics of the polypropylene fibrous filters were as follows: packing fraction 0.06; filter weight $56.0 \mathrm{~g} / \mathrm{m}^{2}$; filter thickness $0.5 \mathrm{~mm}$; mean fiber diameter $15.8 \mu \mathrm{m}$; the weight of filters were measured by the electronic scale. The fiber diameter of the untreated and surfactant pretreated filters was measured by the scanning electron micrograph (SEM) experiments. The filter thickness was measured by a ruler. The packing fraction were calculated by the empirical model of Davies [24].

$$
\begin{aligned}
& \Delta p=\frac{v m U f(\alpha)}{r^{2}} \\
& f(\alpha)=64 \alpha^{1.5}\left(1+56 \alpha^{3}\right)
\end{aligned}
$$

where $\Delta p$ is the pressure drop across the filter; $v$ is the air viscosity; $m$ is the filter thickness; $U$ is the face velocity; $r$ is the fiber radius, and $\alpha$ is the packing fraction.

\subsection{Aerosol Generation System}

Figure 1 presents the experimental set up for the aerosol penetration test of the testing filters. It comprises a constant output atomizer (aerosol generator), a differential mobility analyzer, a neutralizer, a mixing column, a filter holder, a tested filter, an aerosol electrometer, a condensation particle counter used to sample the aerosol concentrations upstream and downstream across the filter, a pressure gauge to measure the pressure drop across the filter, and a flow meter.

Potassium chloride $(\mathrm{KCl})$ and dioctyl phthalate (DOP) were selected as the solid and liquid test aerosols. These two aerosols were often used in several researches [25-28]. The test aerosols were generated in a polydisperse state using a constant output atomizer (model 3076, TSI Inc., USA). Then, the dried and neutralized polydisperse aerosol was electrically classified using a differential mobility analyzer (DMA, model 3080, TSI Inc., USA), to yield monodisperse, singly charged aerosols in the submicrometer-sized include $0.05,0.07,0.10,0.20,0.3$ and $0.45 \mu \mathrm{m}$. The monodispersity and aerosol concentration of the generated particles were measured using a scanning mobility particle sizer (SMPS, model 3936, TSI Inc., USA). The geometric standard deviation (GSD) of these generated particles, based on particle counts varied from $1.10-1.15$. The DOP aerosol concentrations are about $5 \times 10^{3}$ particles $/ \mathrm{cm}^{3}$. The $\mathrm{KCl}$ aerosol concentration are about $4 \times 10^{3}$ particles $/ \mathrm{cm}^{3}$. The aerosols from the DMA passed through a $\mathrm{Kr}-85$ radioactive source (model 3077, TSI Inc., USA), which neutralized them to the Boltzmann charge equilibrium. Then, the tested aerosols were flowed into a mixing column, in which they were diluted with clean air. The diluted aerosol flow was drawn through the filter holder by using the flow meter and the pump.

\subsection{Relative Humidity Control System}

This study considered the effect of relative humidity $(\mathrm{RH})$ on the filtration characteristics. The $\mathrm{RH}$ of the 


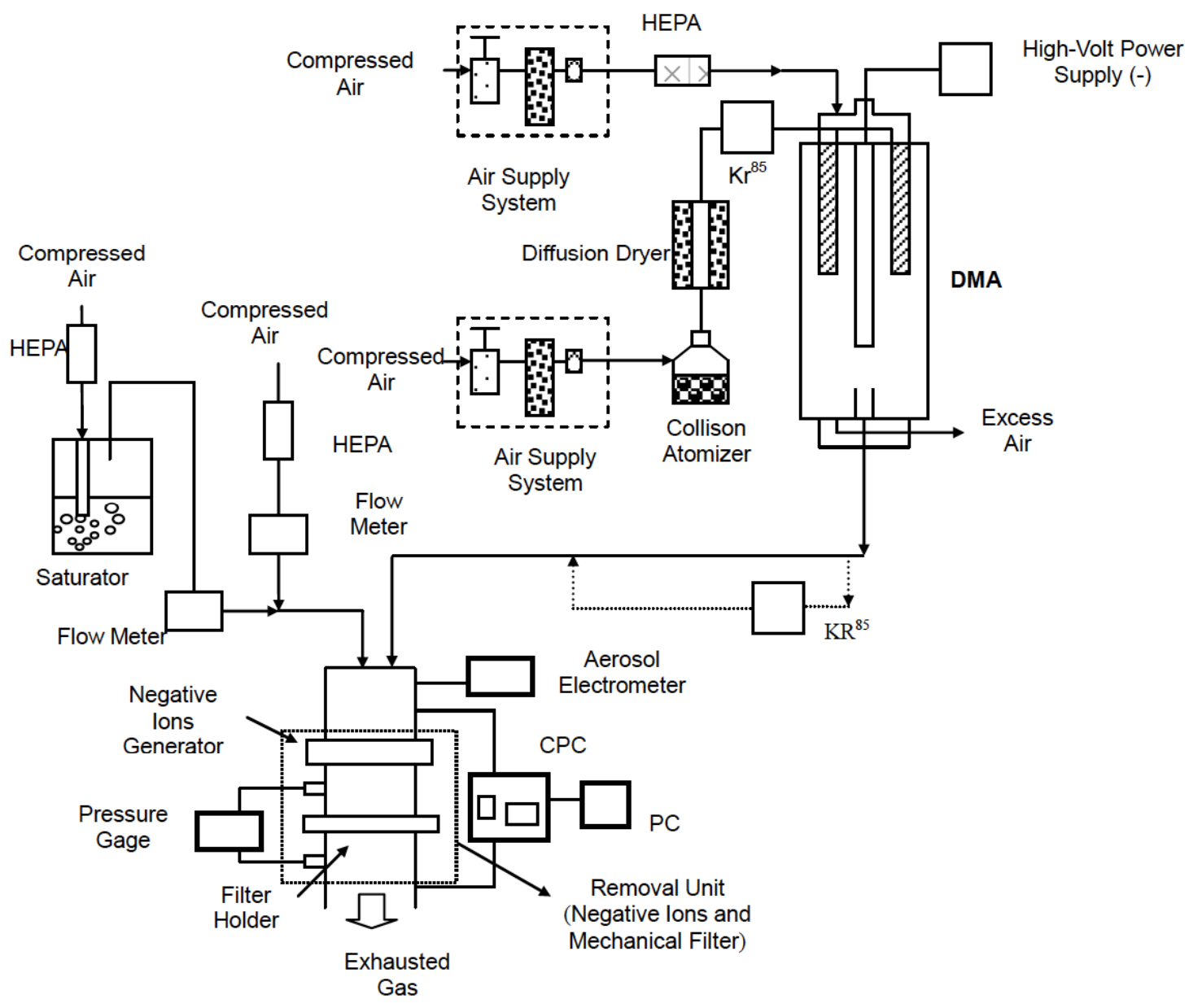

Figure 1: Schematic diagram of the experimental system.

aerosol-flow stream was modified by changing the ratio of the flow rate of the dry gas stream to that of the humidified gas stream generated by a water vapor saturator. The final $\mathrm{RH}$ of the aerosol-flow stream was measured using a hygrometer (model Hygromer A2, Rotronic Inc., Swiss). Two relative humidity, 30 and $70 \%$, for experiments stood for dry and humid conditions, respectively.

\subsection{Aerosol Removal Unit}

The aerosol removal unit comprises a test column made by stainless steel, a negative air ion generator, a filter holder and the tested filter. The column was connected with a ground wire to avoid accumulating the negative air ions on its wall surface. The NAls generator with a negative electric discharge was placed into the test chamber. The electrode of the generator was a cluster of copper needles. Its discharge voltage was controlled with a power supply (model SL300, Spellman Inc., USA) located outside the chamber. The NAls concentrations of $2 \times 10^{4}, 1 \times 10^{5}$, and $2 \times 10^{5}$ NAls $/ \mathrm{cm}^{3}$ were chosen in the work. The NAls concentration was detected with an ion counter (Model ITC-201A, ANDES, Japan).

\subsection{Aerosol Penetration Measurements}

The aerosol concentrations in upstream and downstream of the filter holder were measured using a condensation particle counter (CPC, model 3022, TSI Inc., USA). Therefore, the aerosol penetration through the removal unit was calculated. Each aerosol penetration test was performed in triplicate for a filter. The pressure drop across the test filter was measured using a pressure gauge (model 2000, Dwyer Instruments Inc., USA). The face velocity through the test filter was controlled using a flow meter and a pump.

\subsection{Aerosol Penetration Calculation}

The aerosol penetration through a filter is given by

$P=\frac{C_{\text {down }}}{C_{u p}}$ 
where $\mathrm{C}_{\text {down }}$ and $\mathrm{C}_{\text {up }}$ are the number concentrations measured downstream and upstream of the filter, respectively.

\section{RESULTS AND DISCUSSION}

\subsection{Aerosol Penetration through Filters}

When filters and NAls were unemployed, 0.05 to 0.5 $\mu \mathrm{m} \mathrm{KCl}$ monodisperse aerosols penetrating through the removal unit were sampled using a CPC to ensure that aerosol removal occurred only on the filter surface and not on the holder or any part of the test chamber. Its face velocity ranged from 10 to $20 \mathrm{~cm} / \mathrm{sec}$. Tests were performed at least in triplicate. Figure 2 clearly displays that losses of submicron aerosols through the holder are very small $(<5 \%)$, verifying that background loss of aerosols can be ignored.

Figure 3 showed the aerosol penetration through the mechanical filters without and with NAls when the face velocity and $\mathrm{RH}$ were maintained at $10 \mathrm{~cm} / \mathrm{s}$ and $30 \%$. For $0.3-\mu \mathrm{m}$ aerosols, the aerosol penetration through the filter without NAls was about $92 \%$. The aerosol penetrations through the filters cooperated with $2 \times 10^{4}, 1 \times 10^{5}$, and $2 \times 10^{5} \mathrm{NAls} / \mathrm{cm}^{3}$ were around $79 \%, 52 \%$, and $39 \%$. Obviously, NAls are able to enhance the capture effect on aerosols. It is due to that the NAls would first contact with the particles and cause the particles charged. Then the mechanical filter would collect the charged particles easier. That is working by image electrostatic force (image attracting force is between charged particles and uncharged filter). For understanding the effect of NAls, the factor (penetration with NAIs $_{\text {penetration }}$ withot NAls $)$ was applying to calculate the enhancement of the penetration through the filter with using NAls. The results show that when mechanical filter combining with $\mathrm{NAI}$ concentrations of $2 \times 10^{4}, 1 \times 10^{5}$, and $2 \times 10^{5} \mathrm{NAl} / \mathrm{cm}^{3}$, the overall enhancement factors range of 1.01 to $1.18,1.33$ to 1.80 and 1.59 to 2.42 from the aerosol size from 0.05 to $0.45 \mu \mathrm{m}$. It is indicating that the variation of the aerosol penetration through the filter between with and without using NAls increased with the aerosol size increasing. That is due to that the aerosol was charged with more NAls when aerosol size was getting larger. This phenomenon is consistent with the results from pervious studies by White [29].

According to these results in Figure 3, aerosol penetration through the filters with NAls was decreasing when NAl concentrations was increasing. When mechanical filter combining with $\mathrm{NAI}$ concentrations of $2 \times 10^{4}, 1 \times 10^{5}$, and $2 \times 10^{5} \mathrm{NAl} / \mathrm{cm}^{3}$, the enhancement factors of $0.3-\mu \mathrm{m}$ challenging aerosol were $1.16,1.77$ and 2.36 , respectively. It is because of that the image electrostatic force raised with the aerosols charges increasing. During the filtration process, when the NAls concentration was increasing, the aerosols have more chances to collide with NAls. Thus, testing with higher NAl concentration would cause the charges on the aerosol increased. This phenomenon agreed with the results from previous studies by White [29].

\subsection{Effect of Face Velocity on Aerosol Penetration}

Figure 4 depicts aerosol penetration against aerosol size for the $\mathrm{KCl}$ aerosol at various face velocities (10

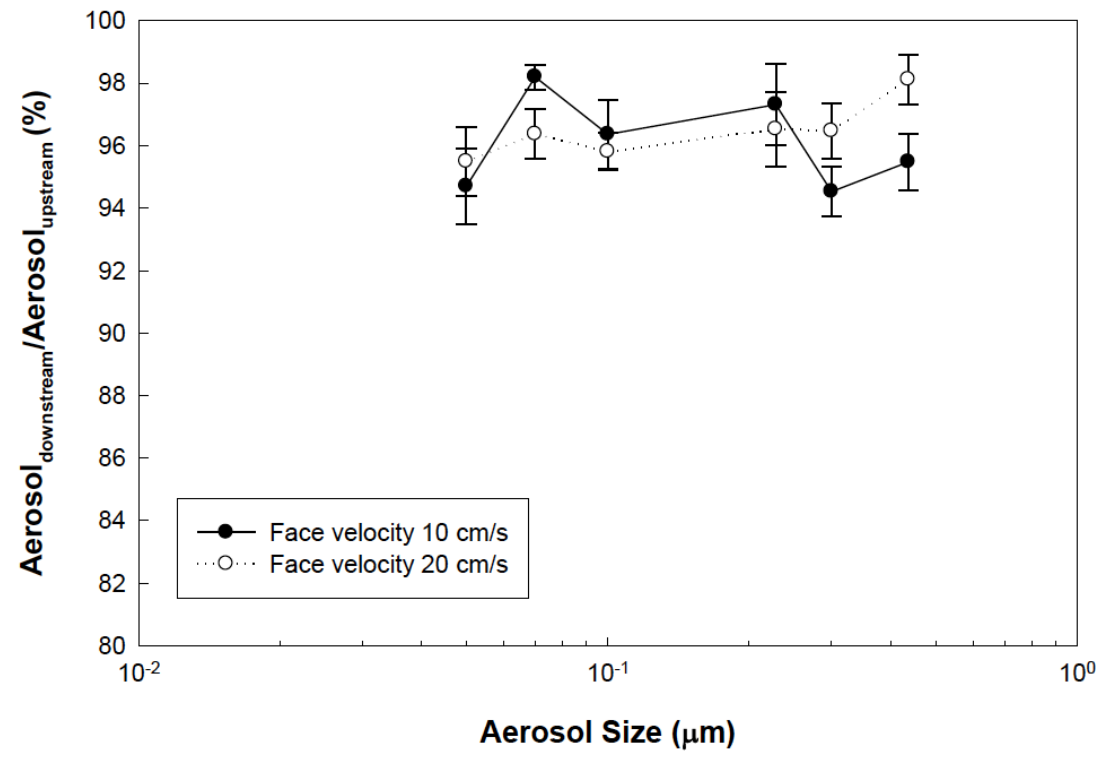

Figure 2: Evaluation of aerosol losses through the test chamber and filter holder. 


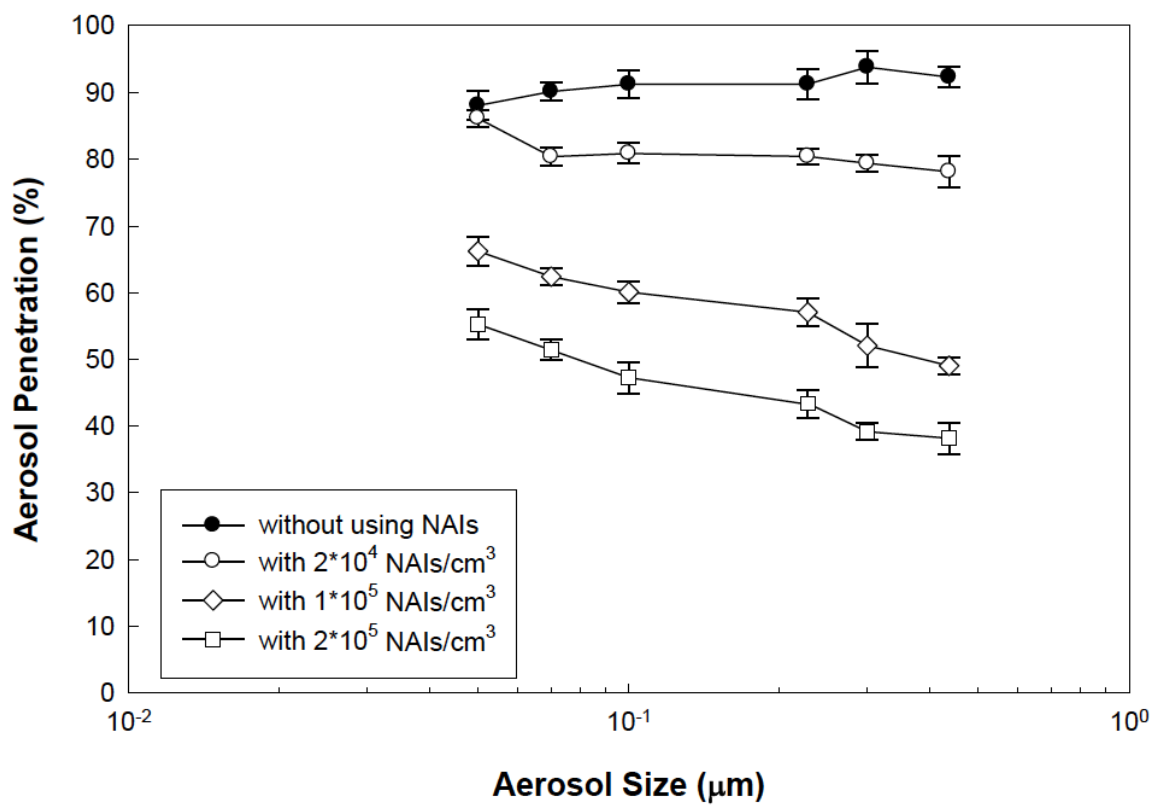

Figure 3: Aerosol Penetration through the filters with negative air ions.

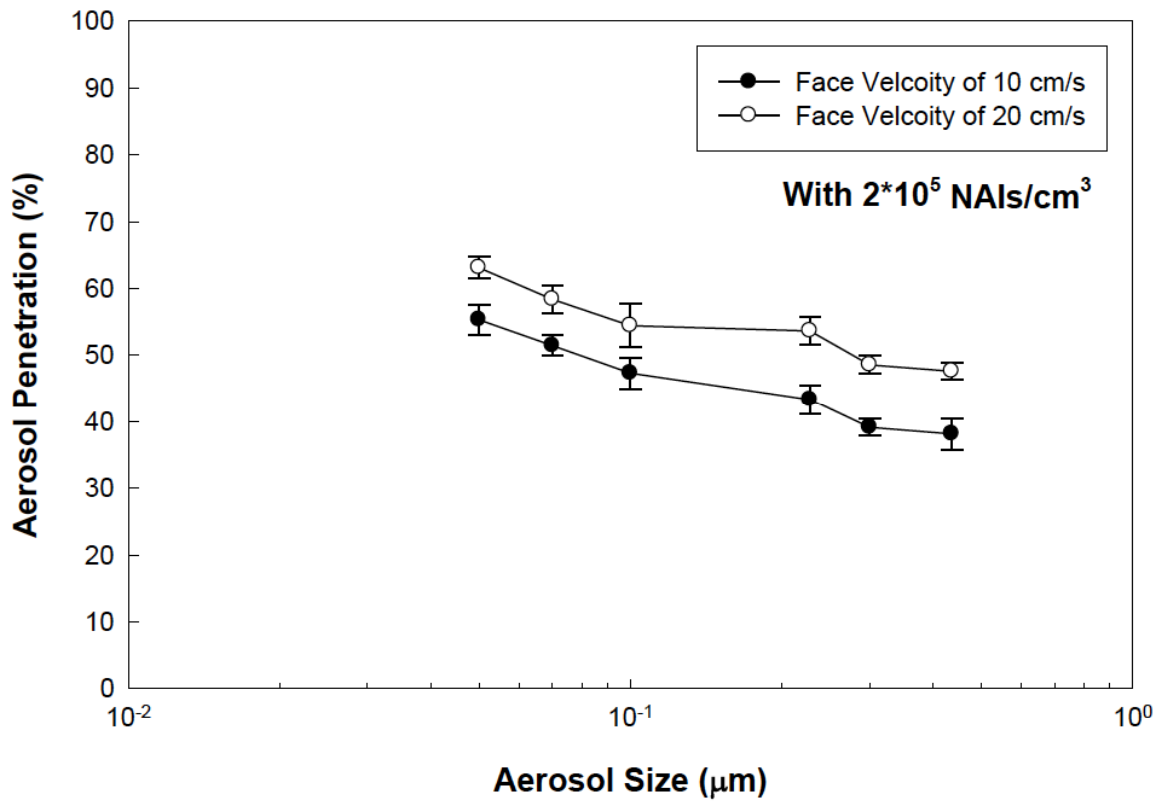

Figure 4: Aerosol Penetration through the filters with NAl at different face velocities.

and $20 \mathrm{~cm} / \mathrm{s}$ ), through the filter with $2 \times 10^{5} \mathrm{NAl} / \mathrm{cm}^{3}$. The result reveals an increase in the penetration of 0.3 $\mu \mathrm{m}$-aerosol through the filter with $2 \times 10^{5} \mathrm{NAl} / \mathrm{cm}^{3}$ from approximately $39 \%$ to $49 \%$ as the face velocity increases from 10 to $20 \mathrm{~cm} / \mathrm{s}$. This result follows from the fact that the principal mechanisms between the submicron charged aerosols and uncharged filter is image electrostatic attraction and diffusion. A higher face velocity leads to a shorter residence time associated with aerosol deposition by electrostatic attraction and diffusion.

\subsection{Effect of Relative Humidity on Aerosol Penetration}

Figure 5 plots the aerosol penetration through the filter with $2 \times 10^{5} \mathrm{NAl} / \mathrm{cm}^{3}$ versus aerosol size at two values of $\mathrm{RH}(30 \%$ and $70 \%)$. The results reveals the penetration of $0.3 \mu \mathrm{m}$-aerosol through the filter with $2 \times$ $10^{5} \mathrm{NAI} / \mathrm{cm}^{3}$ in $\mathrm{RH}$ of $30 \%$ and $70 \%$ were approximately $39 \%$ and $42 \%$. The paired t-test was used to determine the difference of the data for two RHs. A comparison of data for two RHs identified insignificant variation $(P>0.05)$. The analysis results 


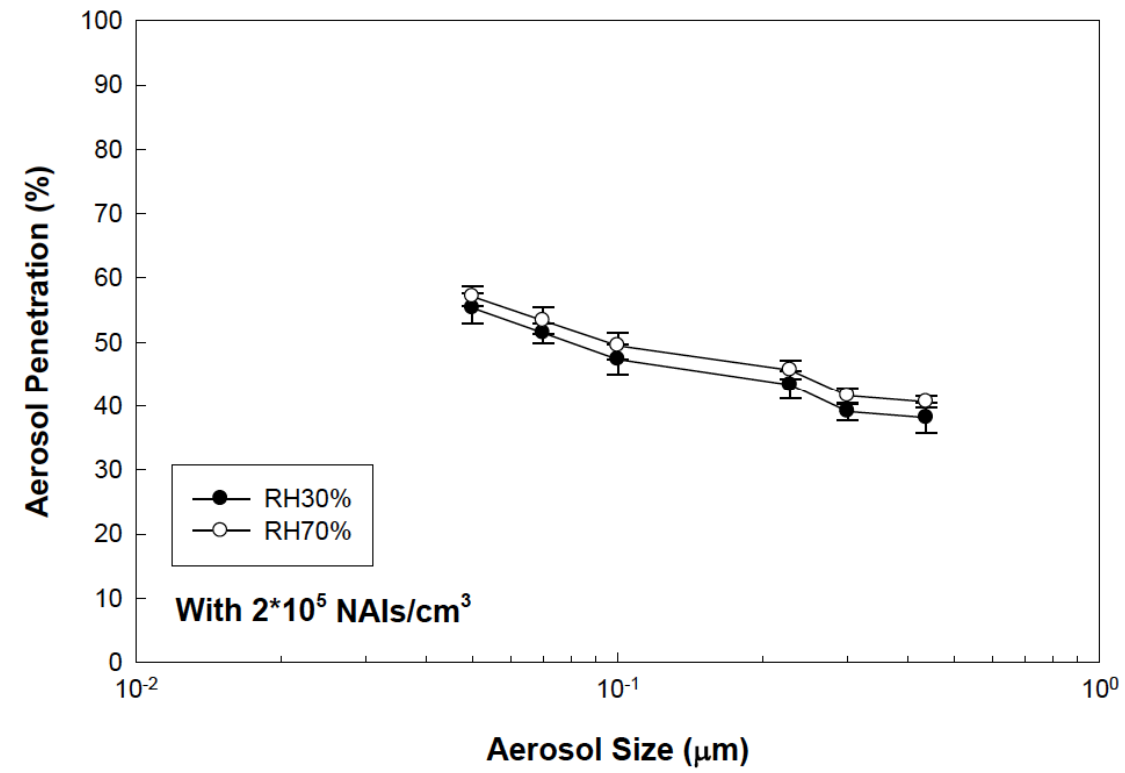

Figure 5: Aerosol Penetration through the filters with NAI at different RHs.

indicate that the penetrations through the filter with NAI were nearly no affected by difference RHs.

\subsection{Effect of Aerosol Type on Aerosol Penetration}

Figure 6 plots aerosol penetration versus aerosol size for filters with $2 \times 10^{5} \mathrm{NAl} / \mathrm{cm}^{3}$ at a face velocity of $10 \mathrm{~cm} / \mathrm{s}$. The penetrations of the $0.3 \mu \mathrm{m} \mathrm{KCl}$ and DOP aerosol were $39 \%$ and $51 \%$. The experimental results reveal that the penetration through the filter with NAls against solid aerosol was lower than that against liquid aerosol. This finding is consistent with those of John et al. ${ }^{[30]}$ which demonstrated that the penetration of liquid aerosols through the filter exceeds that of solid aerosols because aerosol-bouncing effect promotes the penetration of solid aerosols. The bouncing effect is probably the main reason why the penetration of solid aerosols through filters exceeds that of liquid aerosols.

\subsection{Comparison of the Effect of Different Parameters on Aerosol Penetration}

A regression equation was used to identify the effects of different parameters on aerosol penetration. The penetrations of the solid and liquid aerosols are quite different. Hence, the type of aerosol cannot be quantified nor regressed in the equation. The regression equation considered the most significant

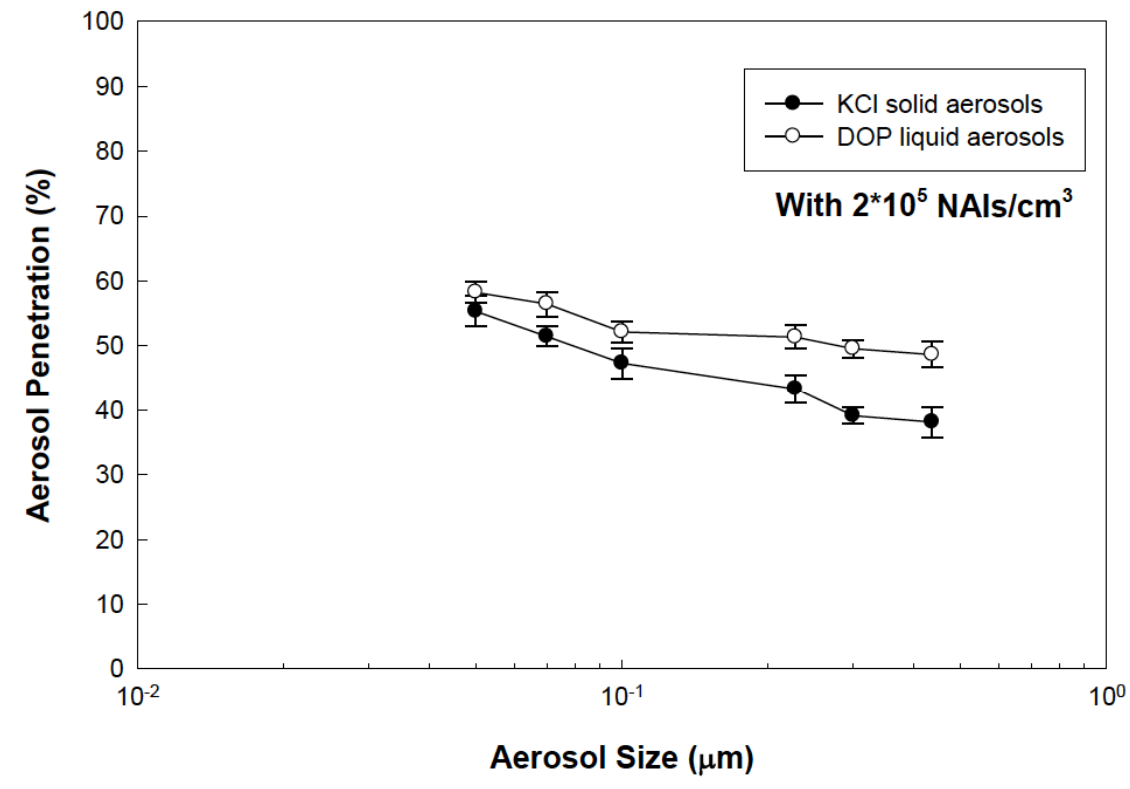

Figure 6: Aerosol Penetration through the filters with $\mathrm{NAl}$ against $\mathrm{NaCl}$ and corn oil aerosols. 
parameters, including aerosol size $(0.05-0.45 \mu \mathrm{m}), \mathrm{NAI}$ concentrations of $2 \times 10^{4}, 1 \times 10^{5}$, and $2 \times 10^{5} \mathrm{NAl} / \mathrm{cm}^{3}$, face velocity $(10$ and $20 \mathrm{~cm} / \mathrm{s})$, and $\mathrm{RH}(30 \%$ and $70 \%$ ). The experimental results can be fit to the following equation:

$P=a d_{p}^{b} N^{c} U^{d} R^{e}$

where $\mathrm{a}, \mathrm{b}, \mathrm{c}, \mathrm{d}$, and $\mathrm{e}$ are constants, $\mathrm{P}$ denotes aerosol penetration, dp represents aerosol size, $\mathrm{N}$ is the concentration of NAls, $U$ denotes the face velocity, and $\mathrm{R}$ represents the relative humidity. The regression analysis yields the following regression equation:

$P=0.53 d_{p}^{-0.53} N^{-0.87} U^{0.46} R^{0.38}$

As demonstrated by the regression analysis, the correlation coefficient $R^{2}$ is approximately 0.914 . Comparison of the coefficients (b, c, d, and e) revealed the effects of different parameters on aerosol penetration. According to the regression equation, the results show that the largest value is $\mathrm{c}$, indicating that the concentration of NAls exerts the strongest influence on aerosol penetration. Moreover, the second highest coefficient value is for $b$, followed sequentially $c$, and $d$. Thus, aerosol size is the second strongest influence on aerosol penetration, followed by face velocity, and $\mathrm{RH}$ has the smallest effect on penetration. An optimal condition could be obtained from the regression equation in the range of this experiment. In this study, the optimal condition is that when aerosol size is 0.05 $\mu \mathrm{m}$, a concentration of NAls is $2 \times 10^{5} \mathrm{NAls} / \mathrm{cm}^{3}$, face velocity is $0.1 \mathrm{~m} / \mathrm{s}$, and $\mathrm{RH}$ is $30 \%$.

\section{CONCLUSIONS}

The aerosol penetration of $0.3 \mu \mathrm{m}$ aerosol through the filter without NAI was about $92 \%$. The $0.3-\mu \mathrm{m}$ aerosol penetrations through the filter with $2 \times 10^{4}, 1 \times$ $10^{5}$, and $2 \times 10^{5} \mathrm{NAl} / \mathrm{cm}^{3}$ were around $79 \%, 52 \%$, and $39 \%$. It indicates that combing mechanical filter with NAls could decrease the aerosol penetration during the filtration process. The results also indicate that the variation of the aerosol penetration through the mechanical filter with NAls increased with the aerosol size. That is due to that the aerosol was easier to be charged when aerosol size was getting larger. The aerosol penetration through the filters with NAls was decreasing when NAl concentrations was increasing. It is because of that the image electrostatic force raised with the aerosols charges increasing. The result reveals an increase in the penetration of $0.3 \mu \mathrm{m}$ aerosol through the filter with $2 \times 10^{5} \mathrm{NAl} / \mathrm{cm}^{3}$ from approximately $39 \%$ to $49 \%$ as the face velocity increases from 10 to $20 \mathrm{~cm} / \mathrm{s}$. Moreover, result implies an increase in the penetration of $0.3 \mu \mathrm{m}$-aerosol through the filter with $2 \times 10^{5} \mathrm{NAl} / \mathrm{cm}^{3}$ from approximately $39 \%$ to $42 \%$ as the $\mathrm{RH}$ increases from $30 \%$ to $70 \%$. The experimental results indicate that the penetrations through the filter with NAls are getting a slight increase when test $\mathrm{RH}$ was raising. The aerosol penetration versus aerosol size for filters with $2 \times 10^{5}$ $\mathrm{NAl} / \mathrm{cm}^{3}$ at a face velocity of $10 \mathrm{~cm} / \mathrm{s}$ against $0.3 \mu \mathrm{m}$ $\mathrm{KCl}$ and corn oil aerosol were $39 \%$ and $50 \%$. The experimental results reveal that the penetration through the filter with NAl against solid aerosol was lower than that against liquid aerosol.

\section{ACKNOWLEDGEMENTS}

The authors would like to thank the Institute of Occupational Safety and Health of Republic of China for financially supporting this research under Contract No. IOSH98-H313.

\section{REFERENCES}

[1] Lance W. Indoor Particles: A Review. J Air Waste Manage Assoc 1996; 46: 98-126. https://doi.org/10.1080/10473289.1996.10467451

[2] Dockery DW, Pope CA, Xu X, Spengler JD, Ware JH, Martha EF, Ferris BG, Spezier FE. An association between air pollution and mortality in six U.S. cities. N Engl J Med 1993; 329(24): 1753-1759. https://doi.org/10.1056/NEJM199312093292401

[3] Koenig JQ, Larson TV, Hamley QS, Rebolledo V, Dumler K, Checkoway $\mathrm{H}$, Wang SZ, Lin D, Pierson WE. Pulmonary lung function in children associated with fine particulate matter. Environ Res 1993; 63(1): 26-38. https://doi.org/10.1006/enrs.1993.1123

[4] Abbey DE, Burchette RJ, Knutsen SF, McDonnell WF Lebowitz MD, Enright PL. Long-term particulate and other air pollutants and lung function in non-smokers. Am J Respir Crit Care Med 1998; 158(1): 289-298. https://doi.org/10.1164/ajrccm.158.1.9710101

[5] Hind WC. Aerosol Technology. J. Wiley and Son: New York 1982.

[6] Baumgartner HP, Löffler F. The Collection Performance of Electret Filters in the Particle Size Range of $10 \mathrm{~nm}-10 \mu \mathrm{m}$. J Aerosol Sci 1986; 17: 438-445.

https://doi.org/10.1016/0021-8502(86)90126-6

[7] Lathrache R, Fissan HJ, Neumann S. Deposition of Submicron Particles on Electrically Charged Filters. J Aerosol Sci 1986; 17: 446-449. https://doi.org/10.1016/0021-8502(86)90127-8

[8] Fjeld RA, Owens TM. The Effect of Particle Charge on Penetration in the Electret Filter. IEEE Transactions on Industry Applications 1988; 24: 725-731. https://doi.org/10.1109/28.6128

[9] Chen CC, Huang SH. The Effects of particle Charge on the Performance of a Filtering Facepiece. Am Ind Hyg Assoc J 1998; 59: 227-233. https://doi.org/10.1080/15428119891010488

[10] Pich J, Emi H, Kanaoka C. Coulombic Deposition Mechanism in Electret Filters. J Aerosol Sci 1987; 17: 29-35. https://doi.org/10.1016/0021-8502(87)90006-1 
[11] Kanaoka C, Emi H, Otani $\mathrm{Y}$, liyama T. Effect of Charging State of Particles on Electret Filtration. Aerosol Sci Tech 1987; $7: 1-13$. https://doi.org/10.1080/02786828708959142

[12] Yang S, Lee WMG, Huang HL, Huang YC, Luo CH, Wu CC, Yu KU. Aerosol penetration properties of an electret filter with submicron aerosols with various operating factors. J Environ. Sci Health, Part A, Environ Sci Eng Toxic Hazard Substance Control 2007; 42(1): 1532-4117.

[13] Luckner J, Wertejuk Z, Podgorski A. Effect of External Electrostatic Field on Filtration Efficiency of Fibrous Filters. Experimental Studies and Numerical Simulations. J Aerosol Sci 1994; 25: S195-S196. https://doi.org/10.1016/0021-8502(94)90328-X

[14] Lee JK, Kim SC, Shin JH, Lee JE, Ku JH, Shin HS. Performance Evaluation of Electrostatically Augmented Air Filters Coupled with a Corona Precharger. Aerosol Sci Tech 2001; 35: 785-791.

https://doi.org/10.1080/027868201753227334

[15] Mermelstein J, Kim S, Stioutas C. Electrostatically Enhanced Stainless Steel Filters: Effect of Filter Structure and Pore Size on Particle Removal. Aerosol Sci Tech 2002; 36: 62-75. https://doi.org/10.1080/027868202753339087

[16] Yang S, Lee GWM. Filtration Characteristics of a Fibrous Filter Pretreated with Anionic Surfactants for Monodisperse Solid Aerosols. J Aerosol Sci 2005; 36(4): 419-437. https://doi.org/10.1016/j.jaerosci.2004.10.002

[17] Agranovski IE, Huang Ruth, Pyankov OV, Altman IS, Grinshpun SA. Enhancement of the Performance of LowEfficiency HVAC Filters Due to Continuous Unipolar Ion Emission. Aerosol Sci Tech 2006; 40(11): 963-968. https://doi.org/10.1080/02786820600833203

[18] Daniels SL. On the ionization of air for removal of noxious effluvia. IEEE Transactions on Plasma Science 2002; 30: 1471-1481. https://doi.org/10.1109/TPS.2002.804211

[19] Grabarczyk Z. Effectiveness of indoor air cleaning with corona ionizers. Journal of Electrostatics 2001; 51-52: 278283. https://doi.org/10.1016/S0304-3886(01)00058-4

[20] Wu CC, Lee GWM. The temporal aerosol size distribution in indoor environment with negative electric discharge. J Aerosol Sci 2003; 34: S999-S1000.
[21] Shi B, Ekberg L. Ionizer Assisted Air Filtration for Collection of Submicron and Ultrafine Particles Evaluation of Long-Term Performance and Influencing Factors. Environmental Science \& Technology 2015; 49(11): 6891-6898. https://doi.org/10.1021/acs.est.5b00974

[22] Lee DH, Jung JH, Lee BU. Effect of Treatment with a Natural Extract of Mukdenia Rossii (Oliv) Koidz and Unipolar Ion Emission on the Antibacterial Performance of Air Filters. Aerosol Air Qual Res 2013; 13: 771-776. https://doi.org/10.4209/aagr.2012.08.0211

[23] Kim HJ, Han B, Kim YJ, Oda T, Won H. Submicrometer particle removal indoors by a novel electrostatic precipitator with high clean air delivery rate, low ozone emissions, and carbon fiber ionizer. Indoor Air 2013; 23(5): 369-378. https://doi.org/10.1111/ina.12037

[24] Davies CN. Air Filtration. Academic Press: London 1973.

[25] Ito $\mathrm{T}$, Otani $\mathrm{Y}$, Inomata $\mathrm{H}$. Performance of air filters cleaned by supercritical carbon dioxide. Separation and Purification Technology 2004; 40: 41-46. https://doi.org/10.1016/j.seppur.2004.01.002

[26] Jasper W, Hinestroza J, Mohan A, Kim J, Shiels B, Gunay M, Thompson D, Barker R. Effect of xylene exposure on the performance of electret filter media. J Aerosol Sci 2006; 37: 903-911.

https://doi.org/10.1016/j.jaerosci.2005.06.008

[27] ASHRAE. Method of Testing General Ventilation AirCleaning Devices for Removal Efficiency by Particle Size. In ANSI/ASHRAE Standard 52.2-1999. American Society of Heating, Refrigerating, Air-conditioning Engineers, Inc, Atlanta 1999.

[28] Jankowska E, Reponen HT, Willeke K, Grinshpuns SA, Choi KJ. Collection of fungal spores on air filters and spore reentrainment from filters into air. J Aerosol Sci 2000; 31: 969-978. https://doi.org/10.1016/S0021-8502(00)00017-3

[29] White HJ. Particle Charging in Electrostatic Precipitation. Trans Am Inst Elect Engrs 1951; 70: 1186-1191. https://doi.org/10.1109/T-AIEE.1951.5060545

[30] Liu BHY, Lee KW. Efficiency of membrane and Nuclepore filters for submicronmeter aerosols. Environ Sci Technol 1976; 76: 345-350. https://doi.org/10.1021/es60115a002 